\title{
Identidades e (não)lugares da maternidade na ciência: discursos e contra-discursos nas mídias contemporâneas
}

DOI: http://dx.doi.org/10.21165/el.v49i3.2644

\section{Lígia Mara Boin Menossi de Araújo' Luciana Carmona Garcia Manzano²}

\section{Resumo}

Em 2017, foi aprovada a lei que deu direito às bolsistas de pesquisa a licença-maternidade; consideramos essa lei como a gênese de um dispositivo que denominamos dispositivo da maternidade na ciência. Assim, empreendemos, neste artigo, a análise de um regime de práticas que compõem uma rede de elementos distintos sobre o fazer científico da mãe. Buscamos responder à seguinte pergunta: Como se constitui o dispositivo da maternidade na ciência? Entendemos dispositivo a partir de Foucault (2014), como uma rede que entrelaça elementos de diferentes ordens, do dito e do não dito - no caso do dispositivo da maternidade, há leis, projetos, grupo de pesquisa, eventos e outros elementos em rede articulando-se em um movimento discursivo e funcionando como um preenchimento estratégico que, como supomos, surge para trazer à tona uma questão que estava posta, até então, à margem.

Palavras-chave: dispositivo; maternidade; discurso.

\footnotetext{
1 Universidade Federal de São Carlos (UFSCar), São Carlos, São Paulo, Brasil; ligiamenossi@gmail.com; https://orcid.org/0000-0003-2047-3019

2 Universidade de Franca (UNIFRAN), Franca, São Paulo, Brasil; luciana.manzano@unifran.edu.br; https://orcid.org/0000-0002-5280-4444
} 


\title{
Mother's identities and (non) places in science: discourses and counter-discourses in contemporary media
}

\begin{abstract}
In 2017, the law granting research fellows the right to maternity leave was approved; we regard this law as the genesis of a device we call "motherhood in science". Thus, in this article, we undertake the analysis of a regime of practices that make up a network of distinct elements about the mother's scientific work. We seek to answer the following question: How is the device of "motherhood in science" constituted? We understand the concept of device from Foucault (2014), as a network that intertwines elements of different orders, the said and the unsaid - in the case of the motherhood device, there are laws, projects, research group, events and other network elements in a discursive movement and functioning as a strategic fulfillment that, as we suppose, arises to fill a gap in bringing up an issue that was in sidelined.
\end{abstract}

Keywords: device; motherhood; discourse.

\section{Introdução}

O conceito de dispositivo, a partir de Foucault (2014), baliza a discussão que empreendemos neste artigo. Assim, situamo-nos, teoricamente, na Análise do Discurso que tem por base os postulados foucaultianos, a partir dos quais podemos entender o dispositivo como uma tomada mais ampla do que a noção de episteme, mais específica, já que toma por base o discurso verbal - o que acontece de modo diferente do dispositivo, compreendido "ele próprio discursivo e não discursivo, sendo seus elementos muito mais heterogêneos" (FOUCAULT, 2014, p. 47). Assim, tomamos o dispositivo como uma via para o olhar sobre o discurso que se abre à análise de objetos das mais diferentes ordens, ou seja, discursos de caráter heterogêneo.

Sargentini (2015) nos explica que Foucault - apoiado em seus estudos anteriores, em As Palavras e as coisas e A arqueologia do saber, nos quais o foco estava nas relações de produção baseadas na teoria econômica e nas relações de significação ancoradas nas teorias linguísticas -, propõe um novo olhar que ocupa um lugar importante em seus projetos, ou seja, pensar quais seriam os instrumentos para estudar as relações de poder. A partir daí, é trilhado um caminho em que se constroem teoricamente as noções de disciplina e dispositivo.

A noção de dispositivo irá vagarosamente substituir a noção de episteme, que seria um dispositivo exclusivamente discursivo, e irá explorar as instituições, as práticas, "o todo social não discursivo" (FOUCAULT, 2014, p. 46). Notamos, então, a construção da fase 
genealógica em que se irão compreender as descontinuidades, as regularidades e as singularidades do objeto de estudo por meio do conceito de dispositivo.

Assim, o que se busca é analisar os tipos de práticas. Por isso, pergunta-se como se dá e não o que seria a loucura e a não loucura, a divisão entre comportamento normal e doença mental; a partir de então, passa-se a considerar que as práticas apresentam uma regularidade, uma lógica, uma estratégia, uma razão próprias. O que propomos, aqui, é fazer a análise de um regime de práticas que compõem uma rede de discursos sobre o fazer científico da mãe, ou seja, o modo como o dispositivo do que denominamos "maternidade na ciência" passa a ser constituído por uma rede de elementos distintos.

Cabe acrescentar que a questão da prática discursiva trazida para nosso trabalho está sedimentada a partir do que propõe Foucault (2000, p. 136) quando afirma que a prática discursiva "é um conjunto de regras anônimas, históricas, sempre determinadas no tempo e no espaço, que definiram, em uma dada época e para uma determinada área social, econômica, geográfica ou linguística, as condições de exercício da função enunciativa". Assim, é possível pensar na construção do dispositivo da maternidade por meio de um regime de práticas discursivas que suscitam elementos distintos e diversos ao discursivizar a temática da mulher na ciência, considerando que há determinações históricas que definem, a partir dos movimentos feministas do século XIX, condições de emergência para a irrupção de enunciados que, inicialmente, fazem falar a mulher e, consequentemente, inscrevem-se na temática da maternidade, ao passo que a evolução tecnológica permitiu uma ampliação do alcance da temática na atualidade.

Neste artigo, tentaremos responder ao seguinte questionamento: como se constitui o dispositivo da maternidade na ciência? Baseando-nos no percurso didático proposto por Sargentini (2015) ao apontar que, na base do modo como se erige o dispositivo por uma rede de elementos, estão três pressupostos, os quais iremos comentar e descrever na tentativa de delinear nossa análise. O primeiro pressuposto seria a formação da questão de pesquisa, o olhar do pesquisador que provoca a ruptura das evidências e aí se constrói o acontecimento, pois "não se trata de analisar uma ruptura historicamente consolidada" (SARGENTINI, 2015, p. 22), mas sim de buscar a emergência de uma singularidade. Para este trabalho, consideramos que o acontecimento se dá por meio da circulação via rede social Facebook ${ }^{3}$ do documentário produzido pelo canal do YouTube Gênero e Número ${ }^{4}$, intitulado Fator $F^{5}$. Esse documentário passou a circular a partir do compartilhamento

\footnotetext{
3 www.facebook.com

4 Gênero e Número. Disponível em: https://bit.ly/33iBBNC. Acesso em: 1 maio 2019.

5 Fator F. Gênero e Número. 25 de junho de 2018. Disponível em: https://www.youtube.com/ watch?v=RukTR9VHcUg\&t=27s. Acesso em: 1 maio 2019.
} 
da página, também do Facebook, Mães que escrevem ${ }^{6}$ com o título de Carreira Científica e Maternidade ${ }^{7}$. Consideramos a circulação desse documentário como a irrupção de um acontecimento constituído por um material discursivo verbal e não verbal, e notamos que o tema é trazido de maneira singular por meio de vídeo nas redes sociais, ao mesmo tempo em que o suporte em que está inscrita essa materialidade audiovisual permite sua circulação ampla, o que possibilita que o tema alcance diferentes sujeitos que ocupam posições diversas na sociedade. A partir daí, surgem alguns questionamentos: como se dão as relações de poder dentro do ambiente acadêmico, das universidades? De que maneira os discursos sobre as mulheres na ciência propagam ou não o estereótipo ${ }^{8}$ da mulher como quem deveria se dedicar somente ao ambiente privado? E, por fim, o que se tem feito para que essa questão tenha seu espaço de reflexão?

Desse modo, vemos a incursão de um segundo pressuposto no qual a pergunta de pesquisa não se instala no interior de uma fonte única: é o momento de observar como se dá esse regime de práticas que compõem a temática para, então, no terceiro momento, olharmos e inventariarmos efetivamente "essas práticas discursivas que estão em rede, entrelaçadas por elementos heterogêneos. Disso decorre a construção do conceito de dispositivo, que comporta a diversidade dos elementos" (SARGENTINI, 2015, p. 22).

\section{Maternidade e ciência: as vidas que não cabem no Lattes}

O dispositivo, segundo Foucault (2014), deve abarcar elementos heterogêneos. Para que se possa identificar determinado dispositivo, é necessário analisar a natureza da rede que entrelaça esses elementos. No tópico que se abre, buscamos analisar o que liga os elementos do que chamamos de dispositivo da maternidade na ciência, portanto, descrevemos elementos das mais diferentes ordens, na tentativa de fazer ver uma prática que permanecia secundária à sociedade e, até mesmo, à comunidade acadêmica.

O dispositivo, então, surge, como veremos, como uma função estratégica dominante por meio de um duplo processo, o de sobredeterminação funcional e o de perpétuo preenchimento estratégico; assim, os efeitos positivos e/ou negativos dessa

6 Disponível em: https://www.facebook.com/watch/?v=194350364571608. Acesso em: 02 maio 2019.

7 Carreira Científica e Maternidade. Disponível em: https://bit.ly/37aM045. Acesso em: 2 maio 2019.

8 Entendemos que estereótipos são imagens previamente construídas e repassadas entre grupos, tanto positiva quanto negativamente, sempre em comparação a um modelo pré-definido e sua função social é inevitável. A análise e o levantamento dos estereótipos objetivam desmistificar tudo aquilo que dificulta as relações interpessoais e a apreensão do real, da originalidade e da inovação, sendo que as ciências sociais, as ciências da linguagem e os estudos literários reconhecem que os fenômenos de estereotipia são inevitáveis (AMOSSY; PIERROT, 2001). 
sobredeterminação irão provocar os ajustes necessários ao preenchimento estratégico suscitado. Para tanto, trouxemos alguns recortes queajudama observara heterogeneidade material que se faz elemento do dispositivo. Ainda sobre o dispositivo, nas palavras de Foucault (2014, p. 45):

\begin{abstract}
[...] um conjunto decididamente heterogêneo, que comporta discursos, instituições, arranjos arquitetônicos, decisões regulamentares, leis, medidas administrativas, enunciados científicos, proposições filosóficas, morais, filantrópicas, em resumo: do dito e do não dito, eis os elementos do dispositivo. O dispositivo propriamente é a rede que se pode estabelecer entre esses elementos.
\end{abstract}

A irrupção do acontecimento no/do discurso se deu com o documentário Fator F produzido pelo canal do YouTube Gênero e Número, como já exposto anteriormente; contudo, consideramos sua gênese a aprovação da lei que deu direito de licença-maternidade às bolsistas de pesquisa em 20179. Anteriormente a essa lei, CNPq e Capes tinham normas internas que concediam às bolsistas a prorrogação da bolsa e, para alguns Programas de Pós-graduação, a extensão dos prazos de entrega dos relatórios de pesquisa. A Capes concedeu o direito à licença maternidade em 19 de dezembro de 2011, com a portaria n. $248^{10}$. A Fundação de Amparo à Pesquisa do Estado de São Paulo (FAPESP) publicou a portaria de n. 05, que concedia a extensão da bolsa por até 120 dias, no dia 8 de julho de $2015^{11}$. Tal portaria foi revogada em 14 de maio ${ }^{12}$ de 2019 e concede a prorrogação da bolsa assim como a de 2015, porém, estende a outras modalidades e é especificada de modo mais detalhado. O que se passou a questionar foi o fato de se ter a licença maternidade (já prevista em leis trabalhistas), porém, não foram consideradas as particularidades da carreira acadêmica, já que, ao sair de licença, a pesquisadora tornase menos produtiva, com pouca ou nenhuma publicação.

Apesar disso, nos editais de concursos, nos de concessão de bolsas e/ou nos de fomento à pesquisa para professoras com ou sem filhos e professores homens, não se leva em conta ou não se "desconta" o período de licença para que a professora-mãe possa ser avaliada de forma relativamente igualitária, considerando seu período de menor produção. Portanto, entendemos que o dispositivo da maternidade na ciência se erige em um dado momento histórico, com a função de responder a uma certa urgência para as mães pesquisadoras.

9 BRASIL. Decreto Lei 13.536 de 15 de dezembro de 2017. Presidência da República. Secretariageral. Disponível em: http://www.planalto.gov.br/ccivil_03/_ato2015-2018/2017/Lei/L13536.htm. Acesso em: 5 set. 2019.

10 Disponível em: https://www.capes.gov.br/images/stories/download/legislacao/Portaria248_19dez2011_LicencaMaternidade.pdf. Acesso em: 5 set. 2019.

11 Disponível em: http://www.fapesp.br/9593. Acesso em: 5 set.2019.

12 Disponível em: http://www.fapesp.br/12872. Acesso em: 5 set. 2019. 
Em 2018, um grupo de pesquisadoras enviou ao Conselho Nacional de Desenvolvimento Científico e Tecnológico $(\mathrm{CNPq})^{13}$ uma carta reivindicando mais igualdade de acesso e concorrência das mulheres com filhos às bolsas e financiamentos no país; desse modo, havia, no documento - que não circulou publicamente e, logo, não tivemos acesso à sua integra, mas ao noticiário sobre o fato, disponibilizado por diversos portais de notícias ${ }^{14}$ diferentes pedidos, e um deles versava sobre a inclusão do período de licença-maternidade no currículo Lattes $^{15}$ como forma de mostrar uma possível interrupção/queda na produção científica no período pós-parto e, assim, impedir comparações consideradas injustas entre pesquisadores homens e mulheres sem filhos em processos seletivos e concursos, pois estes conseguiriam manter a produtividade.

A Profa. Dra. Pamella Mello Carpes ${ }^{16}$, da Unipampa (Universidade Federal do Pampa), foi quem assinou o documento, mas o que fez com que a informação passasse a circular foi o fato de a pesquisadora ter inserido em seu próprio Currículo Lattes a frase: "Mãe de um filho de 14 anos, é atuante na causa das mulheres na ciência" conforme figura 1 a seguir.

13 Disponível em: http://memoria.cnpq.br/o-cnpq. Acesso em: 5 set. 2019.

14 Disponível em: https://g1.globo.com/ciencia-e-saude/noticia/2018/11/13/cientistas-mulherespedem-inclusao-de-periodo-de-licenca-maternidade-no-curriculo-lattes.ghtml. Acesso em: 5 set. 2019.

15 A Plataforma Lattes é um sistema de currículos virtual criado e mantido pelo Conselho Nacional de Desenvolvimento Científico e Tecnológico (CNPq); a Plataforma apresenta de maneira integrada em um único Sistema de Informação dados de Currículos, de Grupos de Pesquisa e de Instituições. Segundo informações coletadas na própria Plataforma, o Currículo Lattes registra todas as atividades já realizadas e as que estão sendo desenvolvidas no momento por estudantes e pesquisadores do país; ademais, hoje é utilizada pela maioria das instituições de fomento, universidades e institutos em virtude da riqueza de informações, da sua credibilidade e abrangência, passou a ser elemento indispensável para análise de mérito e competência das demandas de financiamentos na área da ciência e tecnologia. Disponível em: http://lattes.cnpq. br/. Acesso em: 10 jul. 2019.

16 Endereço do Currículo Lattes: http://buscatextual.cnpq.br/buscatextual/visualizacv. do?id=K4744110D0. Acesso em: 10 jul. 2019. 
Figura 1. Imagem retirada do Currículo Lattes

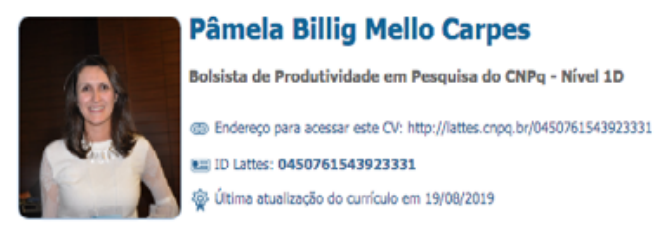

Bolsista de produtividade em pesquisa do CNPq/BF nivel 1D. Senior fellow IBRO/IBE-UNESCO Science of Learning 2018. Ganhou o Prêtnio Para Mulheres na Ciência L'Oreal/UNESCO/Arademia Brasileira de Cî̂ncias em 2017. Finalista do Prêtrnio Donna/ZH Mulheres que Inspiram 2019. Professora Associada na Universidade Fexderal do Pampa (UNIPAMPA), onde lidera o Grupo de Pesquisa em Fisiologia da UNIPAMPA, coordena o Programa POPNEURO: Açøes para divulgaçăo e popularizaçăo da Neurociência e participa do grupo cientistas do Pampa. É docente orientadora do Programa Multicêntrico de Pós-graduaçäo em ciências Fisiológicas/Unipampa, do PPG Bioquímica da UNIPAMPA, e do PPG Fisiologia da UFRGS. Atualmente é coordenadora do Programa Multicêntrico de Pós-graduaçăo em Ciências Fisiológicas/Unipampa, coordenadora substituta do curso de especializaçāo em Neurociência Aplicada à Educaçāo, e membro do Comitê de Ensino da Sociedade Brasileira de Fisiologia (SBFis). Aém da SBFis, é sócia efetiva da Sociedade Brasileira de Neurociência e Comportamento e membro regular da American Physiological Society. Tem experiência cm pesquisa na área de neurofisiologia da memória e ensino de fisiologia e divulgaçăo da (neuro)ciência. É pesquisadora associada da Rede Ciência para a Educação (CDE) e consultora do Escritório da Educação da UNESCO para assuntos relacionados à neurociência aplicada à educação. Mãe de um fillho de 14 anos, é atuante na causa das mulheres na ciência, integra a equipe do Parent in Science, e é membro do Women in Physiology Committe da American Physiological Society. E-mail: pamelacarpes@unipampa.edu.br (Texto informado pelo autor)

Fonte: http://lattes.cnpq.br/0450761543923331

A professora e pesquisadora faz parte de um grupo de mulheres que busca chamar atenção para uma queda na produção científica durante o período de licença-maternidade que se dá para uma maioria significativa de mulheres e pode influenciar de modo negativo suas carreiras científicas.

Esse grupo, criado pela pesquisadora e bióloga Fernanda Staniscuaski, também do Rio Grande do Sul, intitula-se Parent in Science ${ }^{17}$ (figuras 2 e 3). Segundo a professora e pesquisadora, o grupo foi criado para buscar políticas de apoio a essas mães e, também, para desenvolver um projeto de pesquisa que analisa o resultado do impacto da maternidade na produção de mães da área acadêmica. Para participar da pesquisa, é preciso acessar o site do projeto e responder a um questionário específico ${ }^{18}$ (figura 4) aberto a quem quiser contribuir, o que caracterizamos como um dos elementos do dispositivo da pesquisadora mãe que surge como forma de preenchimento estratégico, assim como a edificação do grupo como forma de institucionalizar o pedido.

17 Disponível em: https://www.parentinscience.com/. Acesso em: 22 ago. 2019.

18 Questionário disponível em: https://www.survio.com/survey/d/J4U6Q0Z1V1M5I504N. Acesso em: 22 ago. 2019. 
Figura 2. Símbolo do Grupo de Pesquisa

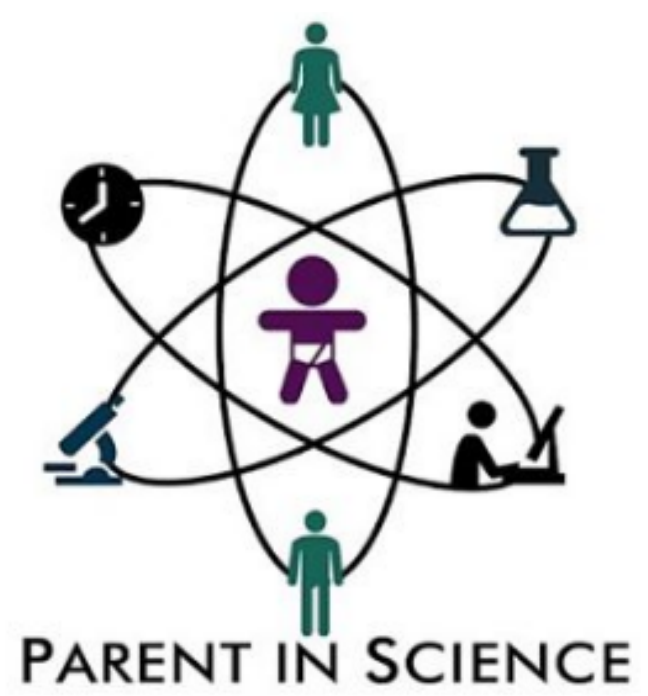

Fonte: https://www.parentinscience.com/

Figura $\mathbf{3}^{19}$. Imagem do site do grupo

\begin{tabular}{|c|}
\hline Nossas ações \\
\hline $\begin{array}{l}\text { Ao longo de 2017, apresentamos } \\
\text { seminários em diferentes universidades } \\
\text { brasileiras. Foram experiências } \\
\text { fantásticas! Em } 2018 \text { seguiremos com } \\
\text { nossos seminários! } \\
\text { Temos um projeto de pesquisa que visa } \\
\text { entender, profundamente, as } \\
\text { consequências da chegada dos filhos na } \\
\text { carreira cientifica de mulheres e } \\
\text { homens, em diferentes etapas da vida } \\
\text { acadêmica. Para isso, criamos } \\
\text { questionários online, que podem ser } \\
\text { acessados nos links abaixo: } \\
\text { Cientistas mães - Cientistas sem filhos - } \\
\text { Cientistas pais - } \\
\text { Pós-doutorandas - } \text { - Pós- } \\
\text { graduandas }\end{array}$ \\
\hline
\end{tabular}

Fonte: https://www.parentinscience.com/

19 Disponível em: https://www.parentinscience.com/sobre-o-parent-in-science. Acesso em: 22 ago. 2019. 
Figura 4. Imagem do início de um dos questionários específicos

\title{
0 impacto da maternidade na carreira cientifica das mulheres brasileiras - Questionário para PESOUISADORAS MÃES.
}

\author{
A maternidade e a carreira acadêmica/científica \\ Prezada docente, pesquisadora e mãe \\ Estamos buscando traçar um perfil das pesquisadoras que viraram mães recentemente. No momento, estamos nos focando em pesquisadoras que \\ realizam pesquisa cientifica e tenham tido filho(s) a partir julho de 2007. Com estes dados, pretendemos desenvolver estratégias de apoio (tanto \\ pessoal quanto profissional) para auxiliar na conciliação destas duas faces da nossa vida. Esperamos, inclusive, poder auxiliar no desenvolvimento de \\ politicas públicas voltadas à garantia de recursos e condições para o pleno desenvolvimento profissional das mulheres que se encontram nesta fase. \\ Completar este questionário vai nos ajudar a obter os melhores resultados!
}

Fonte: https://www.parentinscience.com/

O estudo apresenta alguns resultados preliminares ao analisar o impacto da maternidade na produção de mães pesquisadoras/cientistas, a partir dos quais afırma a possibilidade de verificar que, após o nascimento do/a filho/a, a pesquisadora mãe se depara com um período de baixa produção que impacta, diretamente, na concorrência com os pares nos editais de fomento à pesquisa e faz com que a maternidade no ambiente acadêmicocientífico, assim como em outros tantos ambientes profissionais, passe a ser vista como prejudicial à carreira (ANDRADE, 2018). A partir da formulação enunciativa que instaura um discurso sobre a maternidade como prejudicial à carreira, é possível observar efeitos de sentido sobre o que não se diz, mas que, igualmente, aciona uma memória discursiva que constrói a subjetividade da mãe e da maternidade: a carreira profissional é prejudicial à maternidade. Ou ainda: maternidade e carreira científica são incompatíveis. Essa memória discursiva ${ }^{20}$ (re)atualiza o sentido de lugar privado legitimado como exclusivo e único para a mulher mãe, o que, em certa medida, deslegitima a maternidade como possibilidade no campo do trabalho científico.

Em 2018, o grupo Parent in Science organizou o I Simpósio Brasileiro sobre Maternidade e Ciência, que aconteceu em Porto Alegre, de 10 a 11 de maio. O evento ganhou espaço na mídia e nas redes sociais e desencadeou uma série de ações, como a inclusão da licença maternidade em editais de bolsas da UFF, UFRPE, UNIPAMPA e FURG ${ }^{21}$. Essa

20 Entendemos aqui a memória a partir do que propõe Pêcheux (2007) quando postula que devemos entender a questão não no sentido psicologista de "memória individual", mas como memória social inscrita nas práticas, construída pelo historiador. Ela deve ser tomada como "estruturação de materialidade discursiva complexa, estendida em uma dialética da repetição e da regularização: a memória discursiva seria aquilo que, face a um texto que surge como acontecimento a ler, vem restabelecer os 'implícitos' (quer dizer, mais tecnicamente, os pré-construídos, elementos citados e relatados, discursos-transversos, etc.) de que sua leitura necessita: a condição do legível em relação ao próprio legível (PÊCHEUX, 2007, p. 52).

21 De acordo com o site: https://www.parentinscience.com/. 
inclusão considera o ano em que a pesquisadora esteve em licença maternidade como período não contabilizado na contagem de publicações para avaliação de currículo e estende o período para os dois anos anteriores ao afastamento. Em 16 e 17 de maio de 2019, aconteceu a segunda edição do Simpósio Brasileiro sobre Ciência e Maternidade em Porto Alegre, na Universidade Federal do Rio Grande do Sul, com o tema: Avanços nas instituições de pesquisa. O evento contou com mesas-redondas e com a apresentação da temática por distintas áreas de investigação. Cabe acrescentar que, no evento, as pesquisadoras e mães puderam contar com um espaço de recreação infantil para seus filhos. Tomamos a organização desses eventos como elementos da construção desse dispositivo, considerando o modo de institucionalização, a discursivização do tema que passa a circular socialmente - e, ainda, o modo arquitetônico de organização do evento, que, rompendo com uma memória que segrega e silencia a criança em certos espaços sociais, favorece a presença de filhos e filhas de pesquisadoras.

O evento, assim como o grupo de pesquisa, tem uma página na rede social Facebook ${ }^{22}$, outra página na rede social Instagram ${ }^{23}$ e, também, um canal no YouTube, nos quais podemos encontrar a divulgação dos Simpósios e das ações do Grupo. Mais especificamente, o canal do YouTube disponibilizou as apresentações de palestras proferidas pelas pesquisadoras de dentro e de fora do grupo. Observando a formulação dos títulos das palestras que foram postas em circulação no canal do YouTube, por exemplo, no dia 10 de maio de 2018, "Mulheres na ciência - forças invisíveis que influenciam a representatividade feminina", em 17 de maio de 2019, "Relatos sobre as ações do grupo de trabalho - Questões de gênero na ciência Capes", chama-nos atenção as questões de representatividade e de gênero, temáticas que trazem à tona a espessura histórica a partir da qual à mulher foram construídos espaços e (não) lugares de legitimidade social. É interessante observar que, nesse sentido, as questões que se inscrevem como porta de entrada para se discutir o fazer científico da mulher mãe se aproximam das questões discursivas cujas análises empreendemos na Análise do Discurso - AD.

Uma das práticas discursivas oriundas do movimento promovido pelo grupo de pesquisa Parent in Science foi a criação da hashtag ${ }^{24}$ \#maternidadenolattes ${ }^{25}$ na rede social Instagram. Ao acessarmos a rede social e digitarmos a hashtag em questão, temos como resultado a apresentação de uma página específica composta por discursos verbais e

22 Disponível em: https://www.facebook.com/parentinscience/. Acesso em: 2 ago. 2019.

23 Disponível em: https://www.instagram.com/parentinscience/. Acesso em: 2 ago. 2019.

24 Entendemos por hashtag: "um segmento linguageiro precedido do signo \#, utilizado originalmente na rede microblog Twitter, mas adaptado para outras plataformas como o Facebook principalmente. Essa associação produz uma tag clicável, inserida manualmente num tweet e permite acessar o fio do conjunto de enunciados que contém essa hashtag" (PAVEAU, 2017, p. 197).

25 Disponível em: https://bit.ly/3fNLIEM. Acesso em: 22 ago. 2019. 
não verbais de outros perfis que incluíram a formulação \#maternidadenolattes em suas postagens, possibilitando a formação de um panorama sobre a temática, que se constrói em uma rede de páginas e perfis.

Figura 52. Chamada para o Congresso Brasileiro de Física Médica de 2019

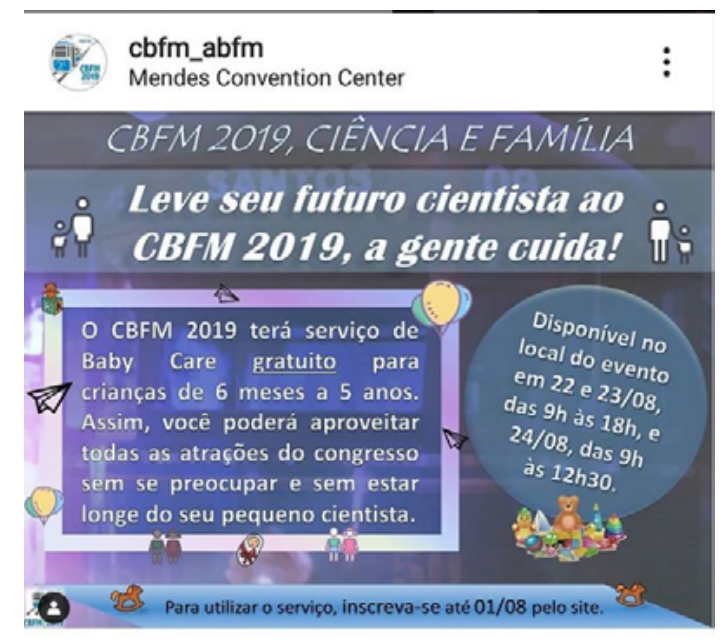

Fonte: Página do Instagram do CBFM

Figura $\mathbf{6}^{27}$. Dados de pesquisa com mães pesquisadoras

\section{MATERNIDADE E MACHISMO}

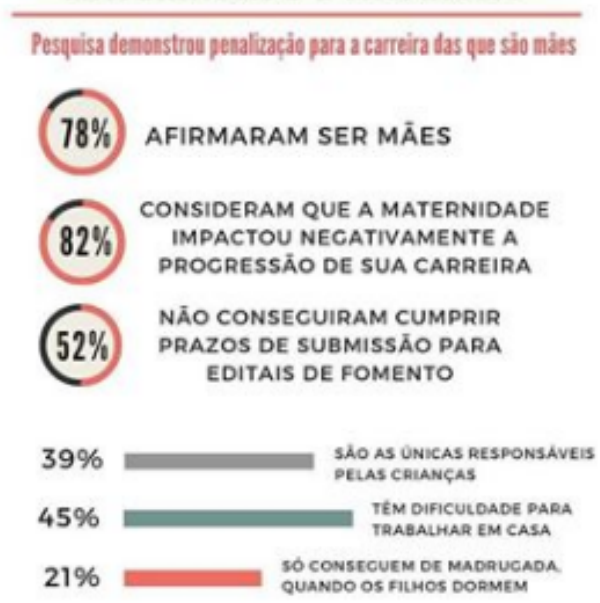

Fonte: Página do Instagram @aliannacardoso

26 Disponível em: https://www.instagram.com/p/B0zR5XpnoCq/. Acesso em: 22 ago. 2019.

27 Disponível em: https://www.instagram.com/p/BzdFuaXIPAn/. Acesso em: 22 ago. 2019. 
Figura $\mathbf{7 2}^{28}$. Entrevista com uma das estudantes da Rede Voa

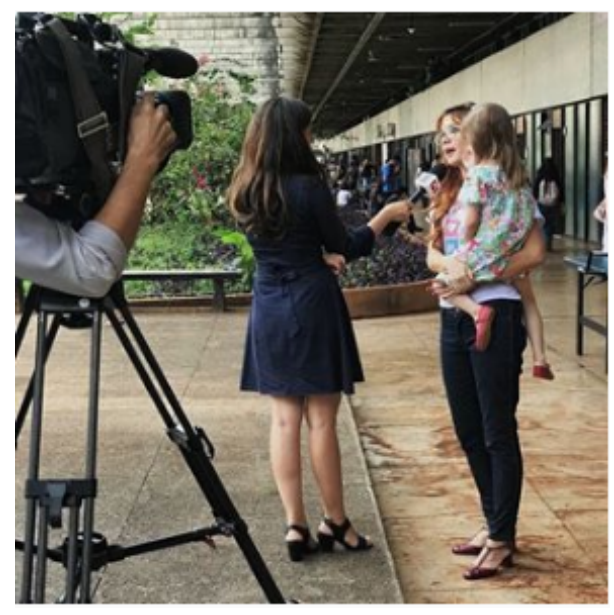

Fonte: Página do Instagram @redevoaunb

Figura $\mathbf{8}^{29}$. Postagem de mestranda grávida escrevendo a dissertação

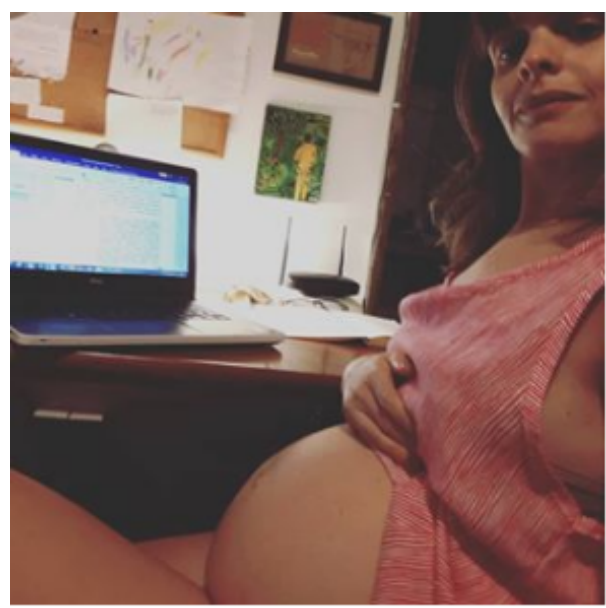

Fonte: Página do Instagram de @linhasdefuga

A visibilidade dada à causa e a criação de uma rede articulada de postagens em favor da inclusão da licença maternidade no Lattes aparece, assim, como elemento reforçador e legitimador do pedido encaminhado ao CNPq.

Além das postagens, três veículos expressivos de comunicação tiveram como tema a maternidade e o trabalho científico: a Folha de São Paulo, com a matéria "Produção científica de pesquisadora cai após maternidade - diz pesquisa" (CANOFRE, 2018), o

28 Disponível em: https://www.instagram.com/p/BvP7zJblXtO/. Acesso em: 22 ago. 2019.

29 Disponível em: https://www.instagram.com/p/BrbcnmBF0-E/. Acesso em: 22 ago. 2019. 
jornal O Estado de São Paulo, com "Maternidade diminui produção acadêmica. Mas não aparece no lattes" (SENA, 2018) e no site G1, com o artigo "Ser mãe e cientista: o que está por trás disso?" (DANTAS, 2018) que, além de trazer uma notícia escrita em seu portal, também mostra um vídeo de dois minutos no qual falam tanto a pesquisadora e bióloga Fernanda Staniscuaski quanto pesquisadoras de outras áreas.

Quanto às ações mais efetivas, encontramos a reportagem de Marasciulo (2019, p. 2), na qual se lê uma nota atribuída ao CNPq em que afirma que "está sensível à questão e recebeu a demanda do grupo 'Parent in Science', encaminhada à Diretoria da agência para avaliação e discussão". Também atribuída à agência, lê-se que ela "já oferece prorrogação das bolsas de mestrado, doutorado, pós-doutorado e produtividade em pesquisa para as bolsistas que se tornam mães, por meio biológico ou por adoção, durante a vigência do auxílio". O CNPq teria confirmado a inclusão na Plataforma Lattes de uma aba específica indicando períodos de licença maternidade e paternidade que entrariam em vigor a partir de 2019. Ainda que não tenhamos encontrado na plataforma Lattes a abertura de campo específico para preenchimento do período de afastamento materno pelas pesquisadoras, observamos mais um elemento significativo na construção do dispositivo da maternidade na ciência: a discussão sobre a implementação de medidas administrativas.

A questão das mulheres mães na ciência, além de ser debatida e ter passado a circular em jornais e revistas, também ganhou espaço em blogs de discussão sobre o feminismo, como o Cientistas Feministas, no qual consta o artigo "Ser mãe e cientista: o que está por trás disso?" (FONTANETO, 2018). Nessa produção, discute-se a importância de reconhecer a maternidade como um elemento que contribui para a sub-representação feminina dentro da ciência, e contrapõe esse efeito de evidência com a inserção da imagem de uma cientista, feita em 1916, junto a sua mesa de trabalho onde estão seus oito filhos.

O dispositivo da maternidade na ciência é, então, alimentado e realimentado pela inscrição em um movimento que, ao mesmo tempo, marca o lugar de sub-representação das mulheres com filhos inseridas no ambiente acadêmico e científico e instaura um lugar diferente: o da naturalização da maternidade na ciência. Há uma sobredeterminação do lugar da mulher na academia em oposição à predominância da atuação acadêmica de reconhecimento e de grandes feitos para o pesquisador homem, perpassadas pela história e pela memória discursiva sobre a subjetividade materna, que dão lugar a um preenchimento estratégico do dispositivo, como, por exemplo, a instauração do espaço "child friendly", de acolhimento à criança filha de pesquisadora, em virtude das lacunas formadas tanto pela relação de disputa de financiamentos de pesquisa cada vez mais escassos como pela necessidade de se provar o trabalho científico quantitativamente, por meio de publicações e atividades diversas, intrínsecas ao trabalho do pesquisador acadêmico. 


\section{Considerações finais}

Neste artigo, buscamos olhar para a construção de um dispositivo que pode ser considerado novo, denominado dispositivo da maternidade na ciência. Nosso esforço teórico-metodológico se fez na direção de inventariar os elementos que parecem compor essa categoria conceitual, no sentido de fixar as características do que, para nós, parece se inscrever na atualidade como dispositivo, porque funciona em rede, a partir de determinadas relações estratégicas, e está composto de elementos heterogêneos que se materializam e passam a circular socialmente. Como analistas de discurso, o conceito de dispositivo nos auxilia a observar um movimento dos discursos, que se dão em dispersão, "e acompanhar as práticas discursivas que de forma ramificada produzem, em um ruído silencioso e contínuo, as transformações dos discursos que circulam na sociedade" (SARGENTINI, 2015, p. 26).

\section{REFERÊNCIAS}

AMOSSY, R.; PIERROT, A. H. Estereotipos y clichés. Traducción y adaptación: Lelia Gándara. 4. reimp. Buenos Aires: Eudeba, 2001 [1997]. Enciclopedia Semiológica.

ANDRADE, R. de. Maternidade no currículo. Projeto de pesquisadoras estima impacto das atividades como mãe na carreira científica. Revista Fapesp, São Paulo, ed. 269, 27 ago. 2018. Disponível em: https://revistapesquisa.fapesp.br/2018/07/19/maternidadeno-curriculo/. Acesso em: 10 jul. 2019.

CANOFRE, F. Produção científica de pesquisadoras cai após maternidade, diz estudo. Folha de São Paulo, Porto Alegre, 13 maio 2018. Disponível em: https://www1.folha.uol. com.br/ciencia/2018/05/producao-cientifica-de-pesquisadoras-cai-apos-maternidadediz-estudo.shtml. Acesso em: 10 jul. 2019.

DANTAS, C. Cientistas mulheres pedem inclusão de licença maternidade no currículo Lattes. 13 de novembro de 2018. Portal G1. Disponível em: https://g1.globo.com/cienciae-saude/noticia/2018/11/13/cientistas-mulheres-pedem-inclusao-de-periodo-delicenca-maternidade-no-curriculo-lattes.ghtml. Acesso em: 2 maio 2019.

FATOR F. Direção: Maria Lutterbach. Pesquisa e reportagem: Carolina de Assis, Giulliana Bianconi e Maria Lutterbach. Gênero e Número. 25 de junho de 2018. Disponível em: https://www.youtube.com/watch?v=RukTR9VHcUg\&t=27s. Acesso em: 1 maio 2018. 
FONTANETO, R. Ser mãe e cientista: o que está por trás disso? 1 de junho de 2018. Cientistas feministas. Blog. Disponível em: https://cientistasfeministas.wordpress. com/2018/07/01/ser-mae-e-cientista-o-que-esta-por-tras-disso/?fbclid=IwAR0TSmEEf1 qR2AAAYbZuWI5VsI1R--dUVqGE_NNODTi5i4MrchmbtxLcmB8. Acesso em: 2 ago. 2019.

FOUCAULT, M. A Arqueologia do saber. Tradução Luiz Felipe Baeta Neves. 6. ed. Rio de Janeiro: Forense Universitária, 2000.

FOUCAULT, M. O jogo de Michel Foucault. In: MOTTA, M. B. da (org.). Genealogia da ética, subjetividade e sexualidade. Ditos e Escritos IX. Rio de Janeiro Forense Universitária, 2014.

MARASCIULO, M. Currículo Lattes permitirá inclusão de licença maternidade e paternidade. Revista Galileu online. São Paulo, 29 de março de 2019. Disponível em: https://revistagalileu.globo.com/Ciencia/noticia/2019/03/curriculo-lattes-permitirainclusao-de-licenca-maternidade-e-paternidade.html. Acesso em: 10 jul. 2019.

MARCELLO, F. de A. O conceito de dispositivo em Foucault: mídia, produção agonística de sujeitos-maternos. Revista Educação e Realidade, v. 29, n. 1, p. 199-213. jan./jun. 2004. Disponível em: https://seer.ufrgs.br/educacaoerealidade/article/view/25426/14752. Acesso em: 10 jun. 2019.

PAVEAU, M.-A. L'Analyse du discours numérique. Dictionnaire des formes et des pratiques. Paris: Hermann, 2017.

PÊCHEUX, M. Papel da Memória. In: ACHARD, P. et al. Papel da Memória. Tradução José Horta Nunes. 2. ed. Campinas: Pontes Editores, 2007. p. 49-57.

SARGENTINI, V. M. O. Dispositivo: um aporte teórico metodológico para o estudo do discurso. In: SOUZA, K. M. de; PAIXÃO, H. P. da P. (org.). Dispositivos de poder/saber em Michel Foucault: biopolítica, corpo e subjetividade. São Paulo: Intermeios; Goiânia, UFG, 2015. p. 17-27.

SENA, V. Maternidade diminui produção acadêmica. Mas não aparece no Lattes. Jornal o Estadão online. São Paulo, 10 dez. 2018. Disponível em: https://arte.estadao.com.br/ focas/capitu/materia/maternidade-diminui-producao-academica-mas-nao-aparece-latte s?fbclid=IwAR0ZQWFG4Io34DHdDI4nc2PtmLuztABLYMwr-oLPaz8cB30wgR50-Vt5qzc. Acesso em: 10 jul. 2019. 